Part of Journal of Research of the National Bureau of Standards, Volume 13, December 1934

\title{
PERMEABILITY OF SYNTHETIC FILM-FORMING MATERIALS TO HYDROGEN
}

\author{
By Theron P. Sager
}

\section{ABSTRACT}

The permeabilities to hydrogen of a number of synthetic film-forming materials spread on closely woven cotton fabric have been determined. Of the films studied, those in which the molecule is rich in hydroxyl groups, regenerated cellulose sheet and polyvinyl alcohol being examples, show very low permeabilities. Cellulose esters and polyvinyl acetate on the contrary give high values. A rough parallelism may be said to exist between the permeabilities of continuous films and the solubility of hydrogen in corresponding types of compounds of simple structure. A comparison of the permeabilities explains the extensive use of materials having hydrophilic-colloidal properties as coating materials for gas-cell fabrics. That satisfactory coating materials may not be limited to highly hygroscopic substances is indicated by the permeabilities obtained with several materials less affected by moisture.

I. Introduction CONTENTS Page

II. Experimental procedure

1. Preparation of samples.

2. Materials......

3. Determination of permeability

III. Discussion of results

\section{INTRODUCTION}

The nature of the process by which gas passes through rubber has been the subject of numerous studies. To Graham ${ }^{1}$ belongs the credit of first noting that the relative rates of diffusion of different gases through rubber bear no relation to their densities or viscosities. He concluded that in the absence of microscopic openings permeation takes place entirely by a process of solution in the rubber on one side and subsequent evaporation from the other side. Concerning the permeability of other continuous films very little information is available in the literature. Kanata ${ }^{2}$ investigated gelatin and celluloid as well as rubber and showed that diffusion through these substances is likewise the result of solvent action. Northrup ${ }^{3}$ also found that collodion membranes behave like rubber toward gases.

If we assume that gases pass through all continuous films by a process of solution, we should be able to predict the rate of diffusion through a particular type of film-forming material, reasoning from

1 Phil. Mag. 32, 401 (1866).

8 Bull. Chem. Soc. Japan 3, 183 (1928).

3 J. Gen. Physiol. 12, 435 (1929). 
the solubility of hydrogen in analogous types of compounds of simple structure.

There are many synthetic film-forming materials that are particularly suited to the study of this relation of composition to permeability because their chemical composition and molecular structure have already been extensively studied. In addition to their value for the present study, many of them are of practical interest in connection with the investigation of gas-cell fabrics conducted in collaboration with the Bureau of Aeronautics, Navy Department. Few structural materials have such rigid and varied requirements as gas-cell fabric. Besides being impermeable to lifting gases, a gas cell, which requires several thousand yards of fabric, must be light in weight, possess a high strength-weight factor, and be capable of withstanding use and handling under varied atmospheric temperatures and humidities. It is of interest to note that two of the earliest balloon fabrics are prototypes of those used today. In 1783 Charles and the Robert brothers built a balloon of taffeta covered with rubber. During the same year, Baron de Beaumanoir constructed a small bailoon lined with goldbeater's skin. In the early nineties, the first dirigibles of the Santos-Dumont type employed varnished fabrics that proved unsuitable because of their tendency to crack, and were soon replaced with heavy rubberized fabric. With the development of the Zeppelin type of airship, the need arose for a lighter and less permeable material. In 1908 the Zeppelin Co. instalied experimental gas cells made with goldbeater's skins, and in 1914 they equipped an entire ship with this type of cells. The objection to cells made of goldbeater's skin is chiefly one of expense, which has become almost prohibitive by the increase in size of the present-day ships. The trend of modern development has been largely directed toward the improvement of rubberized fabrics and the use of gelatin and regenerated cellulose in conjunction with rubber.

The general problem of gas-cell fabrics in relation to airship problems is discussed in detail by Fulton. ${ }^{4}$ The present paper is confined to the discussion of permeability to hydrogen. The application of particular materials to gas-cell fabrication is complicated by problems of plasticizing, seaming, cost, and method of manufacture. In view of these factors, the relative utility of all the materials mentioned herein for actual gas-cell construction is not necessarily indicated by their degree of permeability.

\section{EXPERIMENTAL PROCEDURE}

\section{PREPARATION OF SAMPLES}

With the exception of one commercial sheet material, all the samples were prepared by coating cotton fabric with the film-forming material. This method of preparing the film has the advantage of convenience, particularly with materials which need the structural reinforcement of the fabric, and the advantage of direct information regarding the permeability of the film supported by fabric in the manner customary in the construction of gas cells. The presence of fabric influences the permeation of gases through rubber. Edwards and Pickering ${ }^{5}$ found that spreading rubber on fabric reduced its

4 J. Am. Soc. Naval Eng. 41, 47 (1929).

5 BS Sci.Pap. 16, 327-362 (1920) S387. 
apparent permeability to gases. It has been found that the construction of the supporting fabric has an effect. This is indicated by the values given in table 1 , for rubberized fabrics in which the supporting fabrics had different weights and thread counts. The results indicate that permeability decreases with increase in thread count. In the present work the same fabric was used throughout in order to make the effect of the fabric a constant in the comparison of the permeability ratings for the different coatings.

TABLE 1.-Variation in permeability of rubberized fabrics of different thread count

\begin{tabular}{|c|c|c|c|c|}
\hline \multirow{2}{*}{$\begin{array}{c}\text { Weight of } \\
\text { cloth }\end{array}$} & \multicolumn{2}{|c|}{ Threads per inch } & $\begin{array}{c}\text { Weight } \\
\text { of rubber }\end{array}$ & $\begin{array}{c}\text { Perme- } \\
\text { ability at } \\
1 \text { atmos- } \\
\text { phere }\end{array}$ \\
\cline { 2 - 4 } & Warp & Filling & & \\
\hline oz/yd 2 & & & oz/yd 2 & $1 / \mathrm{m}^{2} / 24 \mathrm{hr}$ \\
1.5 & 132 & 134 & 0.9 & 38.5 \\
1.6 & 198 & 172 & .9 & 24.0 \\
2.2 & 125 & 132 & .9 & 44.0 \\
2.0 & 133 & 124 & .9 & 47.8 \\
1.6 & 134 & 133 & .85 & 36.3 \\
\hline
\end{tabular}

Two methods of preparing the coated fabrics were employed. The simplest method was to tack the raw fabric on a 12 by. 12-inch frame and apply the coating material, dissolved in a suitable solvent, by brushing on several coats. The solvent was allowed to evaporate thoroughly between coatings. This method yields an area of fabric sufficient for the permeability determination. A more laborious and time-consuming method is to apply the coating with a small laboratory spreader. In this the fabric is held under tension and the solution of the coating material is evenly applied with a movable doctor blade. Samples 20 by 50 inches were prepared in this way. By employing the same solvents and applying the same number of coats, approximately the same permeability values are obtained on samples prepared by the two methods.

\section{MATERIALS}

The raw fabric was what is designated as $\mathrm{HH}$ balloon cloth and is the fabric largely employed in gas-cell construction. The specifications of this fabric are as follows:

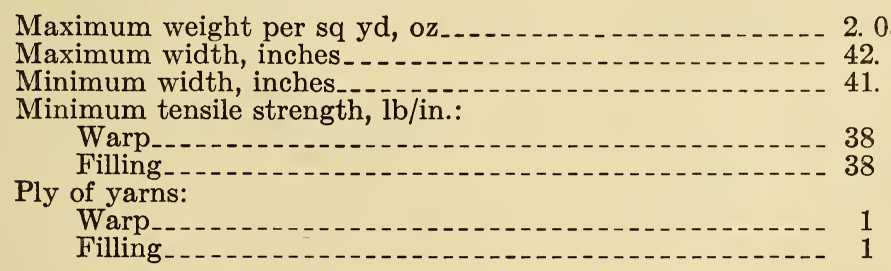

The types of film-forming materials investigated are given in figure 1 . Where possible, their most commonly accepted structures are included.

The regenerated cellulose was sheet cellophane not moistureproofed. The material was approximately 0.001 inch thick. It contained about 16 percent of glycerol as a softener. The polyvinyl alcohol was prepared from polyvinyl acetate of high viscosity by hydrolysis with an alcoholic solution of potassium hydroxide, according to the method described by Staudinger, Frey, and Stark. ${ }^{6}$ The polyvinyl alcohol

${ }^{6}$ Ber. 60, 1789 (1927). 
was washed repeatedly with alcohol and finally dialyzed through washed cellophane. Polyvinyl alcohol is soluble in water and insoluble in other solvents. The cellulose acetate was acetone soluble. The cellulose nitrate was one-half second cotton of lacquer grade. The cellulose aceto-stearate was furnished us as an experimental material.

The polyvinyl acetal was prepared by adding freshly distilled acetaldehyde to an aqueous solution of polyvinyl alcohol containing

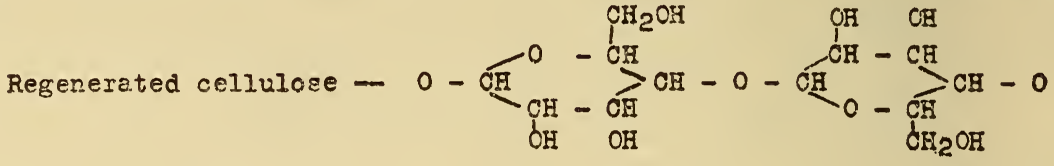

$$
\begin{aligned}
& \text { Polyvinyl alcohol }--\int_{\mathrm{OH}}^{-\mathrm{CH}}-\mathrm{CH}_{2}-\mathrm{CH}_{\mathrm{OH}}-\mathrm{CH}_{2}-
\end{aligned}
$$$$
\text { Cellulose esters - }
$$$$
\text { Polyvinyl acetate -- } \begin{array}{cc}
-\mathrm{CH}-\mathrm{CH}_{2}-\mathrm{CH}_{2}-\mathrm{CH}_{2}- \\
1 \\
\mathrm{OOCCH}_{3} & 1 \\
\mathrm{OOCCCH}_{3}
\end{array}
$$$$
\text { Polyvinyl acetaI - }
$$

$$
\begin{aligned}
& \begin{array}{l}
\text { Polyhydric alcohol- } \\
\text { polybasic acid resin -- } \mathrm{HOOC}-\mathrm{R}-\mathrm{CO}-\mathrm{O}-\mathrm{R}^{\prime}-\mathrm{O}-\mathrm{C} \ldots \\
\mathrm{R}-\mathrm{C}-\mathrm{O}-\mathrm{R}^{\prime}-\mathrm{OH}
\end{array} \\
& \text { Polychloroprene - }-\mathrm{CH}_{2}-\underset{\mathrm{Cl}}{\mathrm{C}}=\mathrm{CH}-\mathrm{CH}_{2}-\mathrm{CH}_{2}-\underset{\mathrm{CI}}{\mathrm{C}}=\mathrm{CH}-\mathrm{CH}_{2}--
\end{aligned}
$$

Polyethyleme sulphide .-

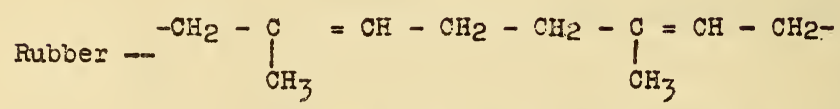

FIGURE 1.-Film-forming materials.

a small amount of hydrochloric acid as a catalyst. The solution was maintained at $65^{\circ} \mathrm{C}$ and thoroughly stirred. The acetal resin precipitated from the solution in the form of a rubbery mass. This was washed to remove adhering acid by comminuting with water, dissolved in ethyl alcohol, and precipitated from the alcohol solution by diluting with water. This was repeated until the material gave no test for acid.

Of the polyhydric alcohol-polybasic acid resins the phthalates, succinates and sebacates were prepared according to methods described 
by Carothers and Arvin, ${ }^{7}$ and by Kienle and Hovey. ${ }^{8}$ The citrates were prepared according to the method described by Sager ${ }^{9}$ in the preparation of tetraethylene glycol citrate. No attempt was made to obtain resins of exceptional purity. In the preparation of products in which both reactants contained two reactive groups, i.e., glycols and dicarboxylic acids, the esterification was carried as nearly to completion as possible. When the tri-reactive materials, glycerol and citric acid, were employed, the esterification was halted by quenching in air just prior to the point of gelation. The fabric-supported films made from these resins represent the resins in this condition without any further heat treatment. The gas-cell fabric coated with Duprene (polychloroprene) represented experimental factory production. The ether-soluble rubber has been described by Smith, Saylor, and Wing. ${ }^{10} \quad$ A small amount of $N$-phenyl- $\beta$-naphthylamine was added as an anti-oxidant. The curing was done with sulphur chloride. The smoked sheet rubber was milled for 10 minutes and was likewise cured with sulphur chloride. The polyethylene sulphide was a rubber substitute known as Thiokol A. This was applied to the fabric by a calendering operation.

\section{DETERMINATION OF PERMEABILITY.}

The permeabilities were all determined by a method developed at the National Bureau of Standards and previously described. ${ }^{11}$ Briefly the method consists in measuring by means of a gas interferometer the difference in refractivity of gas as contained in chambers on the two sides of the fabric. The fabric is held at a temperature of $25^{\circ}$ $\mathrm{C}$ with air at atmospheric pressure on one side of the fabric and hydrogen at an excess pressure of $30 \mathrm{~mm}$ of water on the other side.

The permeabilities to hydrogen are given in table 2 together with the weight per unit area of each film. This weight is obtained by subtracting the weight of the uncoated fabric from that of the coated fabric. All weighings were made at approximately $70^{\circ} \mathrm{F}$ and 65 percent relative humidity. The application of the same weight of coating to each piece of fabric was not feasible. For comparing the relative permeabilities the product of the permeability and weight has been included. For comparing rubberized fabrics this product is useful since for this material the value has been found, within certain weight ranges, to be practically a constant. The propriety of using this product for comparing a variety of materials may be questioned since the validity of regarding this product as a constant for all materials has not been established.

The permeabilities are expressed as liters per square meter per 24 hours. For conversion to cubic feet per square yard per 24 hours this value should be multiplied by 0.0295 .

\footnotetext{
7 J. Am. Chem. Soc. 51, 2568 (1929).

8 (J. Am. Chem. Soc. 51, 509); 52, 3636 (1930).

$\checkmark$ Ind. Eng. Chem., A nal. ed. 4, 388 (1932).

10 BS J. Research 10, 479 (1933) R P544.

11 BS Techn. Pap. 11, (1918) T113. BS Sci.Pap. 16, 327-362 (1920) S387.
} 
TABLE 2.-Permeabilities of film-forming materials

\begin{tabular}{|c|c|c|c|c|c|}
\hline Material & Solvent & $\begin{array}{l}\text { Perme- } \\
\text { ability } \\
\text { at } 1 \text { atm }\end{array}$ & \multicolumn{2}{|c|}{ Weight } & $\begin{array}{c}\text { Permeability } \\
\times \text { weight }\end{array}$ \\
\hline & & $1 / \mathrm{m}^{2} / 24 \mathrm{hr}$ & $0 z / \mathrm{yd}^{2}$ & $\mathrm{~g} / \mathrm{m}^{2}$ & $1 / \mathrm{m}^{2} / 24 \mathrm{hr} \times \mathrm{g} / \mathrm{m}^{2}$ \\
\hline Polyvinyl alcohol......... & Water.... & $\begin{array}{r}0.1 \\
.1\end{array}$ & $\begin{array}{l}1.5 \\
2.0\end{array}$ & $\begin{array}{l}51 \\
68\end{array}$ & \\
\hline Do & ......do_ & .2 & 1.9 & 64 & 13 \\
\hline Polyvinyl acetal..... & Fthano & .7 & 2.9 & 98 & 69 \\
\hline Polyhydric alcohol-polybasi & Etrano & .4 & 2.6 & 88 & 35 \\
\hline Ethylene glycol citrate & -...-do_. & .1 & 3.2 & 109 & 11 \\
\hline Diethylene glycol citr & -...do. & .1 & 3.5 & 119 & 12 \\
\hline Glycerol phthalate. & & .2 & 3.6 & 122 & 24 \\
\hline Ethylene glyc & & .3 & 3.7 & 125 & 38 \\
\hline Diethylene glycol phthal & $\begin{array}{l}\text { Ethyl acetate, } \\
10 \text { percent: }\end{array}$ & .5 & 3.1 & 105 & 53 \\
\hline Glycerol succir & acetone, 90 & 1.0 & 2.4 & 81 & \\
\hline Diethylene glycol succinate... & percent. & .9 & 3.2 & 109 & 98 \\
\hline Glycerol sebacate.. & percenl. & 1.1 & 3. 3 & 112 & 132 \\
\hline Diethylene glycol seba & & 1.6 & 3.0 & 102 & 163 \\
\hline Polyvinyl and cellulose esters: & & & & & \\
\hline Polyvinyl acetate (high viscosity) & Ethanol.. & 4. 7 & 2.7 & 92 & 432 \\
\hline Do & --.--do do-... & 3.1 & 299 & 98 & 304 \\
\hline Polyvinyl acetate (low viscosity & -----do_--. & $1 \mathrm{c}$ & 2.8 & 95 & 950 \\
\hline Do & - & 13 & 2.9 & 98 & 1,270 \\
\hline Cellulose nitrate.. & Mixture 2_. & 7.4 & 3.6 & 122 & 903 \\
\hline Do & $\ldots \ldots$ do & 9.5 & 3.3 & 112 & 1,060 \\
\hline Cellulose acetate.. & Mixture 1.. & 15 & 2.3 & 78 & 1,170 \\
\hline Do & -....-do & 21 & 1.8 & 61 & 1,280 \\
\hline Cellulose aceto-stearate. & Benzol... & 17 & 2.7 & 92 & 1,560 \\
\hline Rubber substitutes: & & & & & \\
\hline Polyethylene sulphide (Thiokol A) _. & & .2 & 9.5 & 322 & 64 \\
\hline 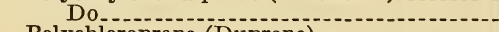 & & .5 & 5.2 & 176 & 88 \\
\hline Polychloropren & & 5.9 & 3.6 & 122 & 720 \\
\hline Ether-soluble rubber & Toluol.... & 9.3 & 2.8 & 95 & 883 \\
\hline Smoked sheet rubber. & 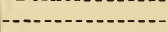 & 19 & 2. 0 & 67 & 1,273 \\
\hline Do.... & & 22 & 1.7 & 57 & 1,307 \\
\hline
\end{tabular}

Solvent mixture 1.-Ethylene dichloride 60 percent, ethyl alcohol 10 percent, methyl cellosolve 10 percent, cellosolve acetate 5 percent, ethyl acetate 15 percent.

Solvent mixture 2.-Toluol 20 percent, ethyl alcohol 60 percent, ethyl acetate 10 percent, cellosolve 10 percent.

\section{DISCUSSION OF RESULTS}

A comparison of the permeability-weight products given in table 2 indicates that the chemical composition of a continuous film is the controlling factor in the process of permeation of hydrogen. In this list of materials are those which have consistently indicated a fibrous or pseudocrystalline structure and those which are characterized by an amorphous structure. The degree of polymerization likewise varies over an enormous range. No clearly defined correlation appears to exist with regard to these properties.

In the case of some of the materials a fairly close parallelism may be drawn between their permeability and the solubility of hydrogen in compounds of the same type but of simple structure. Very low permeabilities are encountered with materials rich in hydroxyl groups such as regenerated cellulose sheet and polyvinyl alcohol. Hydrogen is but slightly soluble in water and glycerol, analogous compounds of simple structure. The behavior of the polyvinyl acetal and the polyhydric alcohol-polybasic acid resins is believed to be attributable to the presence of residual hydroxyl groups in the molecule. The method of preparation of the polyvinyl acetal yields a product which by its behavior toward solvents and its hygroscopic nature indicates incomplete formation of acetal groups in the molecule. It is believed that the presence of the residual hydroxyl groups is more of a determining factor contributing to the low permeability than any inherent char- 
acteristic of the acetal type of compound. The same reasoning may be applied to the polyhydric alcohol-polybasic acid resins. The formation of these resins has been shown to yield polymeric esters which take the form of long chains with the dihydric alcohol-dibasic acid reactants and branched chains in the case of the tri-reactive substances such as glycerol and citric acid. In either case the end groups are represented as $\mathrm{COOH}$ and $\mathrm{OH}$. These resins are all hygroscopic, this property being less pronounced in the case of the sebacates, which have the highest permeabilities in this list of resins.

The behavior of the polyvinyl and cellulose esters indicates the marked effect upon the permeability with the introduction of ester groups in these molecules. A parallelism may be cited with the relatively high solubility of hydrogen in simple esters. The behavior of rubber likewise has its analogy in the simple hydrocarbons.

The comparatively low permeability obtained with polyethylene sulphide (Thiokol A) is of interest inasmuch as this represents a compound of a different type. A parallelism may be suggested between this material and carbon disulphide, in which the solubility of hydrogen is low in comparison with esters and hydrocarbons. It is unfortunate that the calendering operation did not permit the application of a weight of coating comparable with the other materials examined but it is of interest to note that of the two samples examined the permeability-weight products are of approximately the same order of magnitude.

The claim of lower permeability for polychloroprene (Duprene) than natural rubber ${ }^{12}$ is substantiated.

The lower permeability obtained with ether-soluble rubber is of possible significance in indicating the behavior of the more plastic form of the rubber hydrocarbon. In the absence of similar data on the gel-rubber constituent, no definite conclusions can be drawn.

From a practical point of view the relative permeabilities illustrate why, in the construction of gas-cell fabrics, materials having hydrophilic colloidal properties have been used so extensively as coatings on fabric for the retention of lifting gases. For numerous reasons, particularly the variation in weight with changes in atmospheric humidity, the use of highly hygroscopic materials is admittedly undesirable. The permeabilities of several materials which are less affected by the presence of moisture indicates that these or materials of similar nature possibly may be employed.

The work reported in this paper was done as a part of an investigation conducted under Bureau of Aeronautics Project NBS no. 5319 on Gas-Cell Fabrics. The interest of the Bureau of Aeronautics, Navy Department, in this work and permission to publish these results is hereby acknowledged. Acknowledgment is also made to E. C. Creitz, who determined the permeabilities.

Washington, September 27, 1934.

12 Ind. Eng. Chem. 26, 36 (1934). 